\title{
Monoamine Oxidase Inhibition by Major Tanshinones From Salvia Miltiorrhiza and Selective Muscarinic Acetylcholine M4 Receptor Antagonism by Tanshinone I
}

\section{Ritu Prajapati}

Pukyong National University

\section{Se Eun Park}

Pukyong National University

\section{Su Hui Seong}

Pukyong National University

\section{Pradeep Paudel}

University of Mississippi

\section{Fazlin Mohd Fauzi}

Universiti Teknologi MARA

Hyun Ah Jung

Jeonbuk National University

Jae Sue Choi ( $\square$ choijs@pknu.ac.kr)

Pukyong National University

\section{Research Article}

Keywords: Tanshinone I, Parkinson's disease, Monoamine oxidase inhibition, Molecular docking, M4 receptor antagonist

Posted Date: March 12th, 2021

DOI: https://doi.org/10.21203/rs.3.rs-277288/v1

License: (1) (1) This work is licensed under a Creative Commons Attribution 4.0 International License. Read Full License 


\section{Abstract}

Monoamine oxidases (MAOs) and muscarinic acetylcholine receptors (mAChRs) are considered important therapeutic targets for Parkinson's disease (PD). Lipophilic tanshinones are major phytoconstituents in dried roots of Salvia miltiorrhiza that have demonstrated neuroprotective anti-Parkinson effects against dopaminergic neurotoxins and the inhibition of human monoamine oxidase (hMAO)-A. Since MAO-B inhibition is also considered an important therapeutic approach for $P D$, we accessed the potential of three abundant tanshinone congeners in hMAO-A and hMAO-B inhibition in vitro. In our study, tanshinone I (1) exhibited the highest potency against hMAO-A, followed by tanshinone IIA and cryptotanshinone with $\mathrm{IC}_{50}$ values less than $10 \mu \mathrm{M}$. They also suppressed hMAO-B activity with $\mathrm{IC}_{50}$ values lower than $25 \mu \mathrm{M}$. Although the hMAO-A inhibitory activity of tanshinones has been reported, the mechanism of enzyme inhibition and binding sites are yet to be studied. Thus, we conducted enzyme kinetics and molecular docking studies to evaluate the mode of enzyme inhibition and interactions. Proteochemometric modeling further predicted mAChRs as potential targets of $\mathbf{1}$ and an in vitro functional G-protein coupled receptor assay confirmed the selective $\mathrm{M}_{4}$ antagonist nature of $\mathbf{1}$. These findings indicate that $\mathbf{1}$ is a potential therapeutic molecule for managing the motor dysfunction and depression associated with PD.

\section{Introduction}

Parkinson's disease (PD) is the second most prevalent age-dependent neurodegenerative disease (NDD), and is characterized by the progressive degeneration of dopaminergic and non-dopaminergic systems in the substantia nigra, striatal deficiency of dopamine (DA), and intracellular aggregation of a-synuclein. It affects nearly $2-3 \%$ of the elderly population aged over 65 years and presents as motor dysfunctions such as tremor, rigidity, bradykinesia, and postural instability. Besides motor symptoms, non-motor features such as cognitive impairment, depression, dysautonomia, and other social and behavioral abnormalities exacerbate the disease condition $^{1-3}$. Current PD treatment is symptomatic and focused on targeting the dopaminergic system. Levodopa (I-dopa) remains the principal drug used for replenishing reduced dopamine levels in PD, while adjunct therapeutics include catechol-0-methyl transferase (COMT) inhibitors, such as carbidopa, monoamine oxidase B (MAO-B) inhibitors, such as selegiline and safinamide, and dopamine agonists such as pramipexole and apomorphine. Although dopaminergic therapies offer considerable benefits, I-dopainduced dyskinesia (LID) and motor fluctuation, and I-dopa-resistant or non-dopaminergic motor features, as well as non-motor complaints, demand the use of non-dopaminergic treatment options. For example, the Nmethyl-D-aspartate (NMDA) receptor antagonist, amantadine, is used clinically for LID during PD treatment. Other non-dopaminergic neurotransmitters and neuromodulatory systems such as glutamatergic, serotonergic, cholinergic, histaminergic, cannabinoid, and non-adrenergic influence the basal ganglia circuit and are also the targets of ongoing studies to enhance the treatment of PD and alleviate the side effects of DA replacement therapy ${ }^{1,4}$.

Monoamine oxidases (MAOs, EC 1.4.3.4) are the mitochondria-bound flavoenzymes responsible for catalytic degradation of biogenic amines, including monoaminergic neurotransmitters, dietary amines, and xenobiotics in the brain and peripheral tissues. In the human brain, MAOs occur in two isoenzyme forms, MAO-A and MAO-B, which are approximately $72 \%$ identical in amino acid sequence makeup but vary in 
substrate preferences, inhibitor specificities, cell and tissue distribution, and immunological properties. MAOA selectively deaminates serotonin (5-HT), whereas MAO-B preferentially degrades benzylamine and 2phenylethylamine. Dopamine (DA), noradrenaline, and adrenaline are the common substrates for both isoforms of MAOs. Thus, the inhibitors of MAOs are considered as prophylactic and therapeutic agents for NDD s such as PD, Alzheimer's disease (AD), schizophrenia, anxiety, and depression. These conditions are characterized by elevated levels and activities of MAOs, which leads to decreased levels of neurotransmitters, increased oxidative stress resulting from the oxidoreductase activity of the enzymes, and the subsequent degeneration of neurons $\mathbf{s}^{3,5,6}$.

Acetylcholine (ACh) is a prime neurotransmitter in the striatum released by innervated cholinergic interneurons. Cholinergic transmission is proposed to play critical roles in regulating local circuits of striatal complex and modulation of presynaptic dopamine release ${ }^{7,8}$. ACh acts through two types of receptors nicotinic receptors (nAChRs), which are ligand-gated ion channels, and muscarinic receptors (mAChRs), which are G-protein coupled receptors (GPCRs). Even though both of these receptors have significant roles in the peripheral nervous system (PNS) and central nervous system (CNS), mAChRs outnumber nAChRs in the CNS and are involved in regulating neuronal activity and neurotransmitter release in different areas of the brain to maintain neuronal plasticity and regulate multiple motor and cognitive functions. There are five subtypes of mAChRs: $G q$ coupled $M_{1}, M_{3}$, and $M_{5}$, which activate phospholipase $C$ and regulate intracellular calcium mobilization, and $\mathrm{Gi} / \mathrm{o}$ coupled $\mathrm{M}_{2}$ and $\mathrm{M}_{4}$, which inhibit adenylyl cyclase causing a reduction in cAMP levels ${ }^{9,10} . M_{1}, M_{2}$, and $M_{4}$ are the predominant mAChRs in the human brain whereas $M_{3}$ and $M_{5}$ exist throughout the brain at low abundance. Quantitative mAChR localization studies revealed that $M_{1}$ and $M_{4}$ are expressed highly in cortical regions including the hippocampus, whereas $M_{1}, M_{2}$, and $M_{4}$ are abundant throughout the neocortex in the frontal, temporal, parietal, and occipital cortices ${ }^{11,12}$. Concerning their location, relative abundance, and neuronal function, mAChRs have been implicated in different psychiatric and neurological disorders, mainly $A D, P D$, and schizophrenia ${ }^{10,13}$.

The dried roots of Salvia miltiorrhiza, known as Dansen in traditional Chinese medicine (TCM), have been extensively used as traditional medicine for various diseases such as coronary heart diseases, cerebrovascular diseases, AD, PD, renal deficiency, cancer, hepatocirrhosis, and bone loss either as a single herb or in combination with other herbal medicines. Salvia miltiorrhiza is a perennial plant, widely distributed in China, Japan, and Korea ${ }^{14,15}$. Compared to the other parts of plants, the roots of Salvia constitute a high amount of phenolic acids, flavonoids, terpenes, and tanshinones ${ }^{16}$. The major bioactive constituents of Dansen include hydrophilic phenolic acids such as salvianolic acids and hydrophobic diterpenoid quinones such as tanshinones ${ }^{15}$. Salvianolic acids $A$ and $B$ have been reported to have protective effects against liver, pulmonary, and renal fibrosis, and have an antiproliferative effect on breast cancer cells, head and neck squamous carcinoma cells, and pulmonary and hepatic carcinoma cells ${ }^{17}$. Likewise, the lipophilic tanshinones were found to possess a cytotoxic effect on tumor cell lines, anti-inflammatory, anti-oxidant, angiogenic, and neuroprotective effects ${ }^{18}$.

Recent pharmacological studies focusing on the neuroprotective roles of $S$. miltiorrhiza have demonstrated the potential activities of its constituents in NDDs, including AD and PD. Phytoconstituents from this species 
exhibit the inhibition of acetylcholinesterase (AChE), butyrylcholinesterase (BChE), and $\beta$-secretase (BACE1), which are implicated in the pathogenesis of $A D^{15,19,20}$. Tanshinone I (1) showed remarkable suppression of proinflammatory M1 factors, namely, nitric oxide (NO), tumor necrosis factor (TNF)-a, interleukin (IL)- $1 \beta$, and IL-6 expressed in activated microglia. Further, it improved motor function and protected against MPTPinduced neurodegeneration in vivo ${ }^{21}$. Tanshinone IIA (2) in multiple experiments prevented the loss of dopaminergic neurons via different molecular mechanisms ${ }^{22-24}$. Treatment with Danshensu or salvianic acid A displayed enhancement of motor activity and neuroprotection against rotenone-induced Parkinsonism ${ }^{25}$. Overall, these results insinuate that Salvia phytochemicals can act as anti-Parkinson agents. Selegiline and rasagiline are the two well-known MAO-B inhibitors that display protection of dopaminergic neurons from cell death induced by dopaminergic (MPTP, MPP+, 6-OHDA) neurotoxins, ischemia, excitotoxins, and other insults ${ }^{3}$. Previously, Dittman et al. (2004) evaluated four compounds from S. miltiorrhiza, 1, 2, cryptotanshinone (3), and dihydrotanshinone I (Dtan I) for recombinant human MAO-A (hMAO-A) inhibition and found Dtanl as the most active compound with an $\mathrm{IC}_{50}$ value of $23 \mu \mathrm{M}$, followed by $\mathbf{1}, \mathbf{3}$, and $\mathbf{2}$ with $\mathrm{IC}_{50}$ values of $80 \mu \mathrm{M}, 84 \mu \mathrm{M}$, and $>400 \mu \mathrm{M}$, respectively ${ }^{26}$. However, the inhibitory potential against recombinant human MAO-B (hMAO-B) by tanshinones from Danshen has not been evaluated. Moreover, the mechanisms of hMAO-A and hMAO-B inhibition for these compounds are unknown. Thus, in this study, we have investigated the recombinant hMAO-A and hMAO-B inhibition potential of three major tanshinones, $\mathbf{1}, \mathbf{2}$, and 3 , isolated from the roots of $S$. miltiorrhiza. We further examined enzyme inhibition kinetics and intermolecular interactions engaged in enzyme inhibition through kinetics experiments and computational docking. Since pharmacologically active molecules have different mechanisms of action and in silico target prediction helps assess the polypharmacology of a compound, we used computational proteochemometric modeling (PCM) to identify the most probable protein targets of the potent MAO inhibitors. Selecting the most feasible drug target for therapeutic usefulness in PD from among the top ten targets predicted for test compounds, we performed cell and nuclear receptor-based functional GPCR assays and molecular docking to determine the modulatory action on targeted GPCRs and establish the pharmacological role in the management of PD.

\section{Materials And Methods}

Chemicals and Reagents. Test compounds $\mathbf{1}, \mathbf{2}$, and $\mathbf{3}$ of $>98 \%$ purity were obtained by extraction, fractionation, and isolation processes from the dried roots of $S$. miltiorrhiza as described in our published report ${ }^{52}$. The chemical structures of $\mathbf{1}, \mathbf{2}$, and $\mathbf{3}$ are shown in Fig. 1. The recombinant hMAO-A and hMAO-B, Ideprenyl. $\mathrm{HCl}$, clorgyline $\cdot \mathrm{HCl}$, 3-isobutyl-1-methylxanthine (IBMX), and ACh were purchased from Sigma Aldrich (Darmstadt, Germany). Dulbecco's modified Eagle medium (DMEM), Hank's balanced salt solution (HBSS), and 4-(2-hydroxyethyl)-1-piperazineethanesulfonic acid (HEPES) were bought from Invitrogen (Waltham, MA, USA). The remaining reagents and chemicals were purchased from commercial suppliers.

Human Monoamine Oxidase Inhibition Assay. The inhibitory activities on hMAO-A and hMAO-B by three tanshinones 1, 2, and $\mathbf{3}$ were evaluated by using an MAO-Glo ${ }^{\mathrm{TM}}$ chemiluminescent assay kit (Promega, Madison, WI, USA). Experimental procedures for this experiment were as described earlier ${ }^{53,54}$. Briefly, $12.5 \mu \mathrm{l}$ test compound or I-deprenyl was added to a $12.5 \mu \mathrm{l}$ aliquot of beetle luciferin derivative substrate (the initial 
concentrations of hMAO-A and hMAO-B were $160 \mu \mathrm{M}$ and $16 \mu \mathrm{M}$, respectively) in each well of a 96-well plate. Enzyme solution $(25 \mu \mathrm{l})$ was then added to the test samples to initiate the reaction. After an hour of incubation at $25^{\circ} \mathrm{C}$, reconstituted luciferin detection reagent $(50 \mu \mathrm{l})$ was added to each well to stop the reaction and produce a luminescent signal. The final mixture was incubated for an additional 20 minutes at $25^{\circ} \mathrm{C}$. Then, luminescence was recorded on a FilterMax F5 Multi-Mode microplate reader (Molecular Devices LLC, CA, USA). The amount of luminescence is directly proportional to the residual activity of hMOA isoenzymes.

hMAO Enzyme Kinetics Experiment. Enzyme inhibition kinetics was performed with tanshinones 1, 2, and 3 using varying concentrations of hMAO substrate ( 40 to $160 \mu \mathrm{M}$ for hMAO-A kinetics and 4 to $16 \mu \mathrm{M}$ for hMAO-B kinetics). The different concentrations of tanshinones used for kinetic analyses are presented in Figures 2 and 3 . The mode of MAO inhibition was determined from Lineweaver-Burk and Dixon plots, whereas inhibition constants $\left(K_{\mathrm{i}}\right)$ were obtained from secondary plots analyzed using SigmaPlot 12.0 software (SPCC Inc, Chicago, IL, USA).

Prediction of Protein Targets. PCM was used to predict the potential protein targets of $\mathbf{1}, \mathbf{2}$, and $\mathbf{3}$. The experimental model for determining targets was based on a machine learning prototype with a Parzen Rosenblatt window covering 55,079 compounds against 99 human proteins. Representations of compound molecular characterizations were obtained by extended connectivity fingerprints (ECFP_4) generated using jCompoundMapper. The chemical similarity was calculated using the Aitchison-Aitken kernel function. Protein sequences were aligned using the MUSCLE algorithm created by the bui3d package; comparisons between two protein sequences were made and similarities were calculated. Internal and external validation was done for the prediction model, evaluated by sensitivity, specificity, Matthews correlation coefficient, and area under the curve. The detailed PCM is described in an earlier report ${ }^{55}$.

In Vitro Functional GPCR Assay. Cellular and nuclear receptor functional assays were carried out at Eurofins Cerep (Le Bois I' Eveque, France). Recombinant human Chinese hamster ovary (CHO) cells and rat basophilic leukemic (RBL) cells were transfected with GPCR genes of interest $\left(h M_{1} R, h M_{2} R, h M_{3} R\right.$, $h M_{4} R$, and $\left.h M_{5} R\right)$. The experimental conditions for the assay are provided as supporting information in Table S3. The functional assay provided the readouts based on the measurement of calcium ion mobilization (for $\mathrm{G}_{\mathrm{aq}}$ coupled receptors) and cAMP level (for $\mathrm{G}_{\mathrm{ai} / \mathrm{o}}$ coupled receptors).

Measurement of cAMP Level. Stable $\mathrm{CHO}$ cells expressing the transfected CDNA of human $\mathrm{M}_{2}$ receptors were suspended in a medium containing HBSS buffer, complemented with $20 \mathrm{mM}$ HEPES buffer and $500 \mu \mathrm{M}$ IBMX. Whereas the stable human $\mathrm{M}_{4}$ receptor cloned $\mathrm{CHO}$ cells were distributed in HBSS buffer with $20 \mathrm{mM}$ $\mathrm{HEPES} / \mathrm{NaOH}(\mathrm{pH} 7.4), 70 \mathrm{mM} \mathrm{NaCl}, 5.33 \mathrm{mM} \mathrm{KCl}, 1.25 \mathrm{mM} \mathrm{CaCl}_{2}, 0.5 \mathrm{mM} \mathrm{MgCl}_{2}, 0.41 \mathrm{mM} \mathrm{MgSO}_{4}, 0.441$ $\mathrm{mM} \mathrm{KH}_{2} \mathrm{PO}_{4}, 0.3 \mathrm{mM} \mathrm{Na}_{2} \mathrm{HPO}_{4}, 0.1 \%$ glucose and $500 \mu \mathrm{M}$ IBMX. These cell suspensions were distributed into respective assay plates at a density of $10^{4} \mathrm{cells} /$ well and incubated for 5 minutes at $25^{\circ} \mathrm{C}$ with/without test compound or standard. After that, NKH 477 was added to make the final concentrations of either $5 \mu \mathrm{M}$ (for $M_{2} R$ ) or $1 \mu M\left(\right.$ for $M_{4} R$ ) and incubated for 10 minutes at $37^{\circ} \mathrm{C}$. Cells were then lysed, and fluorescence acceptor (D2-labeled CAMP) and fluorescence donor (anti-CAMP antibody labeled with europium cryptate) were dispensed into the cell plate. The resulting mixture was incubated for the next 1 hour at RT. The HTRF 
reading was subsequently taken using a PerkinElmer Envision microplate reader (Waltham, MA, USA) at an excitation intensity of $337 \mathrm{~nm}$, and emission intensities of 620 and $665 \mathrm{~nm}$. The cAMP level was calculated as the ratio of the signal measured at $665 \mathrm{~nm}$ to that measured at $620 \mathrm{~nm}$. The agonist and antagonist activities were illustrated as a percentage (\%) stimulation of control agonist response and as \% inhibition of control agonist response. The agonist effect was determined as the \% of control response to $3 \mu \mathrm{M}$ and $1 \mu \mathrm{M}$ acetylcholine for $\mathrm{M}_{2} \mathrm{R}$ and $\mathrm{M}_{4} \mathrm{R}$, respectively. Likewise, antagonist behavior was represented as the \% inhibition of control response to $0.3 \mu \mathrm{M}$ and $100 \mathrm{nM}$ acetylcholine for $\mathrm{M}_{2} R$ and $M_{4} R$, respectively. The reference agonist for the assay was acetylcholine chloride, and the reference antagonists were methoctramine (for $M_{2} R$ ) and PD 102807 (for $M_{4} R$ ).

Measurement of Intracellular Calcium Levels. Calcium ion influx was evaluated fluorimetrically to determine the functional activity of 1 on $M_{1} R, M_{3} R$, and $M_{5} R$. Stable human $M_{1} R$ and $M_{3} R$ cloned $C H O$ cells were suspended in DMEM buffer complemented with and without $0.1 \%$ delipidated fetal calf serum, and dispensed in a microplate at a density of $3 \times 10^{4}$ cells/well and $2.5 \times 10^{4}$ cells/well, respectively. A fluorescent probe (Fluo4 Direct, Invitrogen) blended with probenecid and 20 M HEPES (pH 7.4), was applied to each well of cells and equilibrated at $37^{\circ} \mathrm{C}$ for 60 minutes, followed by additional 15 minutes at $22^{\circ} \mathrm{C}$. The assay plate was placed in a microplate reader (CellLux, PerkinElmer, Waltham, MA, USA) and the test solution, reference agonist, or HBSS buffer (control) were added to the plate, and ultimately the fluorescence was measured.

Likewise, $\mathrm{hM}_{5} \mathrm{R}$ transfected RBL cells were distributed in HBSS buffer containing $20 \mathrm{mM}$ HEPES and dispensed into the assay plate at a concentration of $2.0 \times 10^{4} \mathrm{cells} /$ well. The fluorescent probe (Fluo8, AAT Bioquest) was blended with probenecid in buffer and added to each well, and left to equilibrate for 60 minutes at $30^{\circ} \mathrm{C}$. The assay plate was placed in a microplate reader (FlipR Tetra, Molecular Device) and the test solution, reference agonist, or HBSS buffer (control) were added. The fluorescence was then measured.

Agonist activity was determined as the \% of control response to $100 \mathrm{nM}, 1 \mu \mathrm{M}$, and $624 \mathrm{nM}$ acetylcholine for $M_{1} R, M_{3} R$, and $M_{5} R$, respectively. Likewise, antagonist behavior was measured as \% inhibition of control response to $3 \mathrm{nM}, 100 \mathrm{nM}$, and $10 \mathrm{nM}$ acetylcholine for $M_{1} R, M_{3} R$, and $M_{5} R$, respectively. The reference antagonist drugs for $M_{1} R, M_{3} R$, and $M_{5} R$ were pirenzepine, 4-DAMP, and atropine sulfate, respectively.

Molecular docking simulation. Autodock4.2 software was used for the molecular docking of compounds 1, 2, and $\mathbf{3}$ to the X-ray crystallographic structures of hMAO-A and hMAO-B, acquired from the RCSB Protein Data Bank (PBD) with IDs 2BXR and 2BYB, respectively ${ }^{56}$. For docking compound 1 with $\mathrm{M}_{4}$ muscarinic receptor, the crystal structure of the $\mathrm{M}_{4}$ receptor bound to tiotropium with RCSB PBD ID 5DSG was used. The sources of the 3D chemical structures of $\mathbf{1}, \mathbf{2}$, and $\mathbf{3}$ were the PubChem Compound database (NCBI) with CIDs 114917,164676 , and 160254. Similarly, crystal structures of harmine, deprenyl, acetylcholine, and tiotropium were also derived from NCBI under CIDs 5280953, 5195, 187, and 5487427, respectively. For docking hMAOs, the water and ligand molecules were eliminated using Discovery Studio (v17.2, Accelrys, San Diego, USA), but the cofactor FAD was retained. AutoDockTool was used for automated docking simulation to add Gasteiger charges automatically and allows rotatable bonds of the ligands to produce different conformers. The AutoGrid program generated the grip maps. The ligand-docking protocol used 10 independent generic 
algorithms. The best docking pose with the least binding score was selected, and the interactions were observed using Discovery Studio.

Drug-Likeness and ADME Prediction of Compound 1. Pharmacokinetic behaviors such as HIA, Caco-2 permeability, BBB, and CNS permeability, and the toxicity profile were predicted by using a web-based pkCSM application ${ }^{57}$ whereas, the solubility, lipophilicity (Log Po/w), drug-likeness, and lead-likeness of 1 were predicted by SwissADME ${ }^{58}$.

\section{Data availability}

The data relevant to this study are provided in the manuscript and supplementary information. Other additional information can be obtained from the corresponding authors upon reasonable request.

\section{Results}

In vitro recombinant human monoamine oxidase inhibition by 1,2 , and 3 . The recombinant human monoamine oxidase (hMAO-A and hMAO-B) inhibition potential of the tanshinones $\mathbf{1}, \mathbf{2}$, and $\mathbf{3}$, isolated from the roots of $S$. miltiorrhiza, were investigated through chemiluminescent in vitro assay using an MAO-Glo kit. All three tanshinones, 1, 2, and 3, showed considerable activity against both hMAO-A and hMAO-B (Table 1). Compounds 1, 2, and $\mathbf{3}$ inhibited hMAO-A with corresponding $\mathrm{IC}_{50}$ values of $2.62 \pm 0.52,6.08 \pm 0.06$, and 8.70 $\pm 0.06 \mu \mathrm{M}$, while also displaying significant hMAO-B inhibition with the corresponding $\mathrm{IC}_{50}$ values of $24.9 \pm$ $3.82,17.5 \pm 0.89$, and $23.1 \pm 2.10 \mu \mathrm{M}$. Bioactive tanshinones were selective toward hMAO-A, 1 being the most potent and selective hMAO-A inhibitor (selectivity index 0.11 ).

Since compounds $\mathbf{1}, \mathbf{2}$, and $\mathbf{3}$ were potent MAO inhibitors, we further performed an enzyme kinetics study to identify the enzyme inhibition modes and $K_{\mathrm{i}}$ values. Lineweaver-Burk plots (1/V vs. $\left.1 / \mathrm{S}\right)$ and secondary plots ( $K_{\text {mapp }} / V_{\text {maxapp }}$ and $1 / V_{\text {maxap }}$ versus inhibitor concentration) were used to determine the kinetic parameters (Figs. 2 and 3). The overall results obtained from the kinetics study are tabulated in Table 1. For hMAO-A inhibition, all three compounds exhibited mixed inhibition with the $K_{\mathrm{ic}}<K_{\mathrm{iu}}$, suggesting a higher affinity for free enzymes than substrate-bound enzymes. $K_{\mathrm{ic}}$ values for $\mathbf{1}, \mathbf{2}$, and $\mathbf{3}$ were $1.69 \pm 0.19,0.72 \pm 0.13$, and 4.99 $\pm 0.34 \mu \mathrm{M}$, respectively.

With hMAO-B, 1 showed a mixed-mode of inhibition with a $K_{\text {ic }}$ value of $25.6 \pm 1.10 \mu \mathrm{M}$ and $K_{\text {iu }}$ value of $17.4 \pm$ $0.78 \mu \mathrm{M}$. Compound 2 showed non-competitive inhibition with an inhibition constant of $13.7 \pm 0.58 \mu \mathrm{M}$ and $\mathbf{3}$ showed competitive enzyme inhibition with a $K_{\mathrm{i}}$ value of $9.33 \pm 0.10 \mu \mathrm{M}$.

Computational investigation into the binding characteristics of tanshinones to hMAOs. Docking simulation of hMAO-A and hMAO-B with compounds 1, 2, and $\mathbf{3}$ were performed using Autodock4.2 software to comprehend the specific binding site and interactions at the orthosteric and/or allosteric sites of the enzymes responsible for the potent inhibitory activities of these compounds. To validate the docking results, hMAO-A (2BXR) was docked with the reference standard harmine and hMAO-B (2BYB) was docked with the reference hMAO-B inhibitor deprenyl. The overall computational simulation results obtained at the best-docked pose for the compounds and MAO-A/B complexes are presented in Figs. 4 and 5. 
Molecular docking of hMAO-A with tanshinones 1, 2, and 3. As shown in Fig. 4, tanshinones 1, 2, and 3 occupied the active site of hMAO-A and interacted with the catalytic binding site with low binding energies of $-10.06,-9.91$, and $-10.07 \mathrm{kcal} / \mathrm{mol}$, respectively. The 1-methylbenzofuran ring of 1 was aligned toward the catalytic aromatic cage comprising Tyr407, Tyr444, and the flavin adenine dinucleotide (FAD) cofactor of hMAO-A and interacted with these residues and FAD through strong hydrophobic bonds such as $\pi-\pi$ stacking, $\pi$-sigma, and $\pi$-alkyl bonds. The $\mathrm{O}$-atom at $\mathrm{C} 11$ further associated with the FAD through a polar $\mathrm{H}$-bond. The tyrosine residues surrounding FAD, Tyr444 and Tyr407, are considered recognition residues crucial for stable substrate/inhibitor binding through $\pi-\pi$ interactions between the aromatic rings, while lle335 and Phe208 of the active site are responsible for substrate selectivity ${ }^{27-29}$. The 1-methylnaphthalene moiety of 1 further linked with substrate-specific residues Ile335 and Phe208 with aromatic $\pi$-sigma and $\pi-\pi$ stacking interactions. Other active site amino acid residues in the ligand-enzyme complex formation are lle180, lle35, and Leu337. Compounds $\mathbf{2}$ and $\mathbf{3}$, which differ in the 1,2-ene group in their benzofuran ring structure, faced toward the important catalytic site constituting FAD, Tyr407, and Tyr444 through their 6,6dimethylnaphthalene moiety. Interactions with these catalytic residues together with Phe352 and Tyr69 occurred via two methyl substituents. While the 1-methylbenzofuran-10,11-dione moiety participated in interactions with many active site residues of hMAO-A such as Ile335, Ile325, Leu337, Ile 180, Cys323, Phe208, Val210, and others as shown in Fig. 4F,J.

Additionally, $\mathbf{1}, \mathbf{2}$, and $\mathbf{3}$ could position in the allosteric binding sites of the hMAO-A enzyme with similar orientations and binding energies of $-7.87,-7.3$, and $-8.67 \mathrm{kcal} / \mathrm{mol}$, respectively. Interactions with amino acid residues such as His488, Phe112, Trp128, Tyr121, and Tyr124 through hydrophobic bonds were common in these three compounds (Fig. 4D,H,L). Compounds 1 and $\mathbf{2}$, which have the same 1methylnaphtho[1,2-g]furan-10,11-dione moiety, anchored with identical residues of allosteric sites - His488 and Thr208 through $1-\mathrm{CH}_{3}$ and $11-0$ groups. All three compounds also showed an electrostatic $\pi$-anion association with Glu492.

Molecular docking of hMAO-B with tanshinones 1, 2, and 3. Even though the tanshinones 1, 2, and $\mathbf{3}$ showed their most efficacious activity on hMAO-A inhibition, these compounds can also suppress hMAO-B significantly as indicated by their $\mathrm{IC}_{50}$ values. To discover the structural activity relationship for the potent activity and selectivity of tanshinones in repressing hMAOs, we conducted a computational study of the compounds with hMAO-B.

The molecular docking of 1 with hMAO-B involved interactions with catalytic recognition site residues Tyr398 and Tyr435 and the cofactor FAD600, which are considered vital for the stable inhibition of the enzyme, through its 6-methylnaphthalene group (Fig. 5A,B). The hMAO-B consists of two cavities, one substrate cavity and a second hydrophobic cavity adjacent to the substrate cavity that separates the active site and the entrance cavity of the hMAO-B. The compound also connected hydrophobically with the residues Cys 172 , Leu171, Tyr326, Ile199, and Ile198, present in the second cavity of hMAO-B. In addition, the docking study revealed that compound 1 was involved in allosteric site binding through different types of interactions polar H-bonding with Thr196 (through 3-O) and Arg127 (through 10,11-O), electrostatic bonding with Asp123 (by the o-quinone moiety) and Glu483 (via 6-methylbenzene ring), and hydrophobic $\pi-\pi$ stacking, $\pi-\pi \mathrm{T}$ shaped, alkyl and $\pi-a l k y l$ bonding to Gly194, lle477, Arg120, and Thr479. 
Compound 2 also exhibited interactions with both the catalytic and allosteric site residues of hMAO-B with binding energies of $-10.29 \mathrm{kcal} / \mathrm{mol}$ and $-7.98 \mathrm{kcal} / \mathrm{mol}$, respectively. As with 1 , the compound could anchor with the Cys172 via a H-bond to the 11-O group, and with Leu199 and Leu171 via hydrophobic interactions. From binding pose analysis of 2 at the catalytic site, it was observed that the 6,6-

dimethylcyclohexane ring projected outside the entrance cavity and interacted with the allosteric site residues Pro104, Phe103, Trp119, and Leu164 (Fig. 5E,F). The in silico simulation also revealed that 2 can bind to the amino acid residues Val106, Tyr112, Arg120, and Glu483, of the allosteric site (Fig. 5G,H). The docking revealed that 1-methylfuran moiety of $\mathbf{2}$ could orient in two ways, either facing toward the catalytic site or toward the allosteric area making it comparatively capable of binding in either way.

Compound 3 interacted with known catalytic site residues of the enzyme such as Leu171, lle198, Ile199, Tyr316, Cys176, Ile316, and Tyr398, along with Leu164 and Leu167 (Fig. 5I,J).

In silico target prediction of tanshinones 1,2, and 3. PCM is a computational technique that combines information from the ligand and related targets within a single machine learning model to explore the bioactivity of compounds on multiple related protein targets, simultaneously. PCM is a quantitative biomodeling technique that can predict the affinity and selectivity of compounds across the panel of targets $^{30-32}$. Our study used PCM to identify the possible targets for compounds $\mathbf{1}, \mathbf{2}$, and $\mathbf{3}$. Table 2 lists the top 10 predicted targets for the compounds, ranked in the order of their normalization rate (NR). We selected muscarinic acetylcholine receptors for further experiments from the list of protein targets since these GPCR receptors are associated with NDDs. Only compound $\mathbf{1}$ showed the likeliness to modulate muscarinic receptors.

\section{Muscarinic acetylcholine $M_{4}$ receptor antagonist action of tanshinone I and molecular docking study. A}

functional GPCR assay that was conducted by measuring CAMP and $\mathrm{Ca}^{++}$mobilization showed the selective antagonist nature of 1 on $\mathrm{mAChR} \mathrm{M}_{4}$ (Table 3 ). The antagonist activity of $\mathbf{1}$, represented by percentage inhibition of control agonist response, was found to be $56.1 \pm 2.40 \%$ at $100 \mu \mathrm{M}$.

A computational study was used to investigate how the compound interacts with the $\mathrm{M}_{4}$ receptor and at what target site the compound binds. As Fig. 6 shows, 1 binds at the orthosteric site of $M_{4}$ with a binding energy of $-8.77 \mathrm{kcal} / \mathrm{mol}$. Hydrophobic connections with the catalytic residues Tyr439 and Tyr433, via $\pi-\sigma$ bonds, and Ala200 and Ala203, via $\pi$-alkyl bonds, were similar to the cognate agonist, ACh, and the cognate inverse agonist, tiotropium, respectively. However, the polar $\mathrm{H}$-bond and electrostatic interactions were not feasible with 1, which might be because of its anionic nature and the lack of hydrolyzable polar functional groups in its structure. Aromatic interactions with orthosteric alanine and tyrosine residues might have resulted in the increased binding affinity of the compound. Additional alkyl bond linkage with Cys442 was observed through the $-\mathrm{CH}_{3}$ substituted phenanthrene moiety.

Prediction of pharmacokinetics and toxicity profile of tanshinone I. Prediction of the pharmacokinetic profile for 1 by SwissADMET showed drug likeliness but no lead-likeness due to violation of a condition where XLOGP3 is less than $3.5^{33}$. It was predicted to have lipophilicity of $2.44(\log \mathrm{Po} / \mathrm{w})$ and solubility of -6.91 (poorly soluble). The pkCSM application indicated high human intestinal absorption (HIA) of $\mathbf{1}(>90 \%)$ along 
with its probability to readily cross the blood-brain barrier (BBB) and reach the CNS. The pkCSM showed no toxicity on hepatocytes but is likely to be positive in the Ames test (Table 4).

\section{Discussion And Conclusions}

Herbal medicines have been used in TCM for numerous ailments in China and other Asian countries for thousands of years. The roots of $S$. miltiorrhiza are a widely popular component of TCM used either alone or combined with other herbs; for instance, the Danshen dripping pill (known as Fufang Dansen Diwan in China) is composed of S. miltiorrhiza, Panax notoginseng, and Dryobalanops aromatica ${ }^{14}$. The phytochemicals of Dansen have been clinically proven to possess multiple health-promoting effects, especially as cardiovascular and anticancer agents ${ }^{34,35}$. The neurological effects of $S$. miltiorrhiza such as anti-Alzheimer through the inhibition of cholinesterase ${ }^{19}, \beta$-secretase ${ }^{15}$, and amyloid $\beta(A \beta)$ aggregation ${ }^{36}$, attenuation of brain edema and the protection of $\mathrm{BBB}^{37}$, and the protection of dopaminergic neurons against neurotoxins ${ }^{21,24}$, have highlighted the potential of its constituents in neurological disorders.

Our study investigated the hMAO isoenzyme inhibition potential of three abundant tanshinones of $S$. miltiorrhiza, supplemented with enzyme kinetics and molecular docking studies. Our research found that the test compounds were more active against hMAO-A than hMAO-B, consistent with a previous report ${ }^{26}$. Among the test compounds, 1 showed the most potent and selective hMAO-A inhibition with an IC 50 value of $2.62 \pm$ $0.52 \mu \mathrm{M}$ and $K_{\mathrm{i}}$ value of $1.69 \pm 0.19 \mu \mathrm{M}$. It showed a mixed-mode of enzyme inhibition, corroborating with the catalytic and allosteric site binding in docking studies. This result signifies that $\mathbf{1}$ can bind to both the free and substrate-bound hMAO-A enzymes. Compounds $\mathbf{2}$ and $\mathbf{3}$ also exhibited a strong mixed-mode of hMAO-A inhibition with $\mathrm{IC}_{50}$ values of $6.08 \pm 0.06 \mu \mathrm{M}$ and $8.70 \pm 0.06 \mu \mathrm{M}$ and $K_{\mathrm{i}}$ values of $0.72 \pm 0.13 \mu \mathrm{M}$ and $4.99 \pm$ $0.34 \mu \mathrm{M}$, respectively. The potency of hMAO-A inhibition obtained in our work differs from that of the previously published article ${ }^{26}$ because a lower concentration of these compounds was required to inhibit $50 \%$ of the enzyme activity. This variation might be because of the different experimental conditions and enzymes used.

Although tanshinones 1, 2, and $\mathbf{3}$ show selectivity toward hMAO-A, the ability of the compounds to suppress hMAO-B cannot be neglected because they displayed enzyme inhibition at concentrations below $25 \mu \mathrm{M}$. MAO-B accounts for $80 \%$ of total MAO activity and major dopamine oxidation in the striatum of the human brain compared to MAO-A. Moreover, MAO-B increases with aging and neurodegenerative diseases such as $P D$ and $A D$, even though the age-related decline of many neurons and related neurotransmitters and enzymes occurs $^{38,39}$. Juxtaposing the efficacy of the tested tanshinones for various functionalities related to NDDs, tanshinones 1, 2, and $\mathbf{3}$ were selective and notable inhibitors of hMAO-A with moderate action against hMAO$B$. The inhibition potential of these compounds was more significant for BChE than for AChE, suggesting their selectivity toward $\mathrm{BChE}^{20}$. Among the test compounds, 1 portrayed the most efficacious for inhibiting BACE $1^{15}$ and $A \beta$ aggregation ${ }^{36}$.

The in silico study revealed that the 1-methylbenzofuran ring with single methyl substitution at C6 found in 1 was necessary for the strong $\pi-\pi$ interactions with the critical catalytic site residues of hMA0-A. The 6,6dimethyl substitution will orient the molecules in such a way that methyl groups will interact with the Tyr444, 
Tyr407, and FAD600, not allowing the aromatic sandwich interaction between the compounds and the enzyme, important for potent enzyme inhibition. Likewise, docking with hMAO-B showed that the structural features of 1 allowed it to interact with catalytic substrate-binding sites comprising FAD600, Tyr398, and Tyr 435 along with the second cavity residues through different polar and non-polar bonding. In accord with the kinetic study, the inhibition mechanism established by the computational study showed catalytic and allosteric inhibition for $\mathbf{1}$ at hMAO-B binding sites. Whereas $\mathbf{2}$, which inhibited hMAO-B non-competitively, was found to bind to both the catalytic and allosteric site residues more or less to the same extent. Similarly, 3 was engaged in the active site of hMAO-B interacting with most of the known second cavity loop residues and one substrate residue, Tyr398, of hMAO-B, which complies with its competitive binding mode.

Besides the selective hMAO-A inhibition, tanshinones could target other proteins and enzymes. Among the high NR score targets, mAChRs have been linked to non-dopaminergic motor and non-motor symptoms of $\mathrm{PD}$, and the only compound presumed to modulate these receptors through the in silico method was 1 . The cell and nuclear receptor-based functional assay showed 1 to be a selective $\mathrm{M}_{4}$ antagonist. The in silico study revealed that the compound occupies the orthosteric binding site of the $M_{4}$ receptor through hydrophobic interactions with active site residues, which were described previously by Thal et al. $(2016)^{40}$.

Although several studies have demonstrated the pharmacological benefits of tanshinones, the pharmacokinetics study showed low bioavailability due to their low solubility and low permeability. Our in silico prediction of the pharmacokinetic characteristics of 1 revealed poor solubility and low permeability (Caco-2 permeability is only $1.40 \mathrm{~cm} / \mathrm{s}$ ). As predicted for CNS and BBB permeability, a recent in vivo pharmacokinetic and tissue distribution study using rats showed the distribution of $\mathbf{1}$ into the brain, with the highest amount reaching the liver, kidney, and lungs after oral administration. Also, the combination of tanshinones had greater bioavailability (represented by the area under the curve and maximum concentration values) than single tanshinones administered orally, except for 1 and Dtan I, which showed similar pharmacokinetic values compared to that of the tanshinone mixture. Among tanshinones 1, 2, 3, and Dtan I, 1 had the most extended half-life ${ }^{41}$. The ability of 1 to protect from hepatotoxicity was observed by Park et al. (2009), which conforms with the predicted non-hepatotoxic property ${ }^{21,42}$. Though the prediction shows 1 to be Ames positive indicating its mutagenic ability, its anticancer effects together with neuroprotective and anti-inflammatory effects have been verified experimentally $21,36,43,44$.

Neuropathological investigations in the autopsied brain of patients with PD indicate that the disease manifests as dopaminergic neuronal degeneration in the ventrolateral substantia nigra in the early stage, which progresses to the midbrain and other regions of the brain in the later stages, along with increased levels of MAO-A and MAO-B ${ }^{2,45}$. Since DA is the common substrate for both MAO isoenzymes, the inhibitor of these enzymes prevent the oxidative degradation of DA and increase the synaptic DA level. The globally elevated MAO-A is correlated with mood disturbances such as sadness or depression in different psychiatric diseases and prodromal states, and therefore represents a pharmacological target for correcting mood and depressive illness ${ }^{45}$. In addition to the dopaminergic system, the cholinergic system has also been implicated in the etiology of the disease and is regarded as one of the pharmacological targets for the management of motor symptoms associated with PD. 
$M_{4}$ is the major mAChR subtype in the striatum, where it is enriched in $D_{1}$ DA receptor-expressing spiny projection neurons (SPNs) comprising the basal ganglia direct pathway ( $\left.D_{1}-S P N s\right)$, but not $D_{2}$ expressing indirect-pathway SPNs. This is a critical pathway for motor activation. Studies using the $M_{4}$ deletion from $D_{1}$ SPNs have found genetically modified mice to be hyper-locomotive, with elevated baseline DA, and more sensitive to dopaminergic stimulants than littermate controls ${ }^{46}$. Tzavara et al. (2004) demonstrated that $\mathrm{M}_{4}$ muscarinic receptors regulate the dynamic balance between the cholinergic and dopaminergic systems. In the $\mathrm{M}_{4}$ knockout mouse model, it was observed that the loss of $\mathrm{M}_{4}$ receptors enhanced the DA basal levels and induced dopaminergic hyperexcitability in response to psychostimulants, suggesting that $\mathrm{M}_{4}$ receptors as crucial muscarinic autoreceptors regulate DA neurotransmission and dopaminergic activity ${ }^{47}$. A recent study also concluded that blocking $\mathrm{M}_{4}$ receptors on striatal cholinergic neurons enhances dopamine release and rescues the striatal DA deficit ${ }^{48}$. Thus, selective $M_{4} R$ antagonists could improve parkinsonian motor disability by relieving $\mathrm{M}_{4}$-mediated inhibition of DA release in the striatum.

In former investigations that focused on the implications of diterpenoids from S. miltiorrhiza in AD, tanshinone congeners appreciably attenuated scopolamine-induced cognitive impairments and reversed learning and memory dysfunctions induced by scopolamine and diazepam. These observations indicated that the memory-enhancing effect of tanshinones might be associated with the cholinergic signaling activation or the inhibition of cholinesterases that led to increased acetylcholine levels ${ }^{49}$. Although the cholinesterase inhibition properties of tanshinones 1, 2, and $\mathbf{3}$ are known, and the nAChR antagonist effects of the lipophilic extract of $S$. miltiorrhiza have been reported, whether the cognitive improvement by these tanshinone congeners is directly linked to cholinergic signaling remains unknown ${ }^{19,20,49,50}$. In our in silico target prediction, we found that muscarinic $\mathrm{M}_{2}$ and $\mathrm{M}_{4}$ receptors are the most relevant targets for 1 , and our in vitro experiment determined the $\mathrm{M}_{4}$ selective antagonist property of 1 , which might rule out a role for tanshinones in the stimulation of muscarinic receptors for learning and memory improvement. Kim et al. (2009) found that the activation of the ERK/CREB signaling pathway by 1 in the hippocampus reversed $\mathrm{GABA}_{A}$ receptor agonist and NMDA receptor antagonist-induced cognitive dysfunction ${ }^{51}$.

Due to the extreme similarity of the conserved residues that comprise the orthosteric sites of muscarinic receptors $\left(M_{1}-M_{4}\right)$, designing a drug to act selectively at one of the mAChR is challenging. Since $M_{4}$ represents a crucial target for $P D$ and selective $M_{4}$ antagonists could produce therapeutic benefits avoiding unwanted cholinergic side effects, the discovery of safe and novel $\mathrm{M}_{4}$ selective antagonists is vital. To date, very few $\mathrm{M}_{4}$ selective antagonists are known, and most clinically available anti-muscarinic agents are either non-selective or only partially selective ${ }^{40}$. Our present work identifies that compound 1 from $S$. miltiorrhiza is a fully selective antagonist of $\mathrm{M}_{4}$. Our investigation into the monoamine oxidase inhibitory activity of compounds derived from roots of $S$. miltiorrhiza led to the acknowledgment that 1 is a very potent and selective hMAO-A inhibitor that has a mixed-mode of enzyme inhibition. In addition, the other tanshinones, 2 and $\mathbf{3}$, possess potent and selective hMAO-A inhibition activity with moderate activity against hMAO-B. Among the three tanshinones, 1 exhibited the most favorable activities along with the reported abilities to inhibit cholinesterases, BACE1, and $A \beta$ aggregation, which suggests it may have a promising role in 
neurodegenerative diseases. Overall, this study presents 1 as a potential plant-derived therapeutic agent to alleviate motor symptoms and depression in PD patients.

\section{Declarations}

\section{Acknowledgements}

This research was supported by the National Research Foundation of Korea (NRF) grant funded by the Ministry of Science and ICT (No. 2020R1C1C1008331).

\section{Author contributions}

J.S.C. and H.A.J. conceived and designed the study. R.P. and P.P. performed the in vitro assays to determine the biological activities, S.E.P. and S.H.S. conducted molecular docking study, and F.M.F. did target prediction of the tanshinones. R.P. wrote the manuscript with input from all authors. All authors have approved the final version of the paper.

\section{Corresponding authors}

Jae Sue Choi - Department of Food and Life Science, Pukyong National University, Busan 48513, Republic of Korea; Tel: +82-51-629-7547; Email: choijs@pknu.ac.kr https://orcid.org/0000-0001-9034-8868

Hyun Ah Jung - Department of Food Science and Human Nutrition, Jeonbuk National University, Jeonju 54896, Republic of Korea; Tel: +82-63-270-4882; Email: jungha@jbnu.ac.kr

\section{Competing interest}

The authors declare no competing financial interest.

\section{Ethics declarations}

Our research does not involve animal models or human subjects for the experiments. This study is limited to in vitro enzymes, receptors, and cellular experiments.

\section{Additional information}

The Supplementary information for this paper is available at...

\section{References}

1. Balestrino, R. \& Schapira, A. H. Parkinson disease. Eur. J. Neurol.27, 27-42 (2020).

2. Poewe, W. et al. Parkinson disease. Nat. Rev. Dis. Primers3, 1-21 (2017).

3. Naoi, M. \& Maruyama, W. Monoamine oxidase inhibitors as neuroprotective agents in age-dependent neurodegenerative disorders. Curr. Pharm. Des.16, 2799-2817 (2010). 
4. Gonzalez-Latapi, P., Bhowmick, S. S., Saranza, G. \& Fox, S. H. Non-dopaminergic treatments for motor control in Parkinson's disease: an update. CNS Drugs, 1-20 (2020).

5. Youdim, M. B., Edmondson, D. \& Tipton, K. F. The Therapeutic Potential of Monoamine Oxidase Inhibitors. Nat. Rev. Neurosci.7, 295-309, doi:10.1038/nrn1883 (2006).

6. Manzoor, S. \& Hoda, N. A comprehensive review of monoamine oxidase inhibitors as anti-Alzheimer's disease agents: a review. Eur. J. Med. Chem., 112787 (2020).

7. Dautan, D. et al. A major external source of cholinergic innervation of the striatum and nucleus accumbens originates in the brainstem. J. Neurosci.34, 4509-4518 (2014).

8. Lehmann, J. \& Langer, S. The striatal cholinergic interneuron: synaptic target of dopaminergic terminals? Neuroscience10, 1105-1120 (1983).

9. Thomsen, M., Sørensen, G. \& Dencker, D. Physiological roles of CNS muscarinic receptors gained from knockout mice. Neuropharmacology136, 411-420 (2018).

10. Dencker, D. et al. Muscarinic acetylcholine receptor subtypes as potential drug targets for the treatment of schizophrenia, drug abuse, and Parkinson's disease. ACS Chem. Neurosci.3, 80-89 (2012).

11. Volpicelli, L. A. \& Levey, A. I. Muscarinic acetylcholine receptor subtypes in cerebral cortex and hippocampus. Prog. Brain Res.145, 59-66 (2004).

12. Lebois, E., Thorn, C., Edgerton, J., Popiolek, M. \& Xi, S. Muscarinic receptor subtype distribution in the central nervous system and relevance to aging and Alzheimer's disease. Neuropharmacology136, 362373 (2018).

13. Erskine, D. et al. Cholinergic muscarinic $M_{1}$ and $M_{4}$ receptors as therapeutic targets for cognitive, behavioural, and psychological symptoms in psychiatric and neurological disorders. Drug Discov. Today24, 2307-2314 (2019).

14. Chun-Yan, S., Qian-Liang, M., Rahman, K., Ting, H. \& Lu-Ping, Q. Salvia miltiorrhiza: traditional medicinal uses, chemistry, and pharmacology. Chin. J. Nat. Med.13, 163-182 (2015).

15. Yu, T. et al. Computational insights into $\beta$-site amyloid precursor protein enzyme 1 (BACE1) inhibition by tanshinones and salvianolic acids from Salvia miltiorrhiza via molecular docking simulations. Comput. Biol. Chem.74, 273-285 (2018).

16. Zeng, H. et al. Comparative analysis of the major chemical constituents in Salvia miltiorrhiza roots, stems, leaves and flowers during different growth periods by UPLC-TQ-MS/MS and HPLC-ELSD methods. Molecules22, 771 (2017).

17. Ma, L., Tang, L. \& Yi, Q. Salvianolic acids: potential source of natural drugs for the treatment of fibrosis disease and cancer. Front. Pharmacol.10, 97 (2019).

18. Jiang, Z., Gao, W. \& Huang, L. Tanshinones, critical pharmacological components in Salvia miltiorrhiza. Front. Pharmacol.10, 202 (2019).

19. Ren, Y., Houghton, P. J., Hider, R. C. \& Howes, M.-J. R. Novel diterpenoid acetylcholinesterase inhibitors from Salvia miltiorhiza. Planta Med.70, 201-204 (2004).

20. Senol, F. S. et al. Selective in vitro and in silico butyrylcholinesterase inhibitory activity of diterpenes and rosmarinic acid isolated from Perovskia atriplicifolia Benth. and Salvia glutinosa L. Phytochemistry133, 33-44 (2017).

Page $14 / 24$ 
21. Wang, S. et al. Tanshinone I selectively suppresses pro-inflammatory genes expression in activated microglia and prevents nigrostriatal dopaminergic neurodegeneration in a mouse model of Parkinson $\square \mathrm{s}$ disease. J. Ethnopharmacol.164, 247-255 (2015).

22. Ren, B. et al. Tanshinone IIA prevents the loss of nigrostriatal dopaminergic neurons by inhibiting NADPH oxidase and iNOS in the MPTP model of Parkinson's disease. J. Neurol. Sci.348, 142-152 (2015).

23. Zhang, J., Wang, Y., Ji, X. \& Shu, Z. Tanshinone IIA protects against dopaminergic neuron degeneration via regulation of DJ-1 and Nrf2/HO-1 pathways in a rodent model of Parkinson's disease. Trop. J. Pharm. Res.18 (2019).

24. Zhang, X. et al. Tanshinone IIA protects dopaminergic neurons against 6-hydroxydopamine-induced neurotoxicity through miR-153/NF-E2-related factor 2/antioxidant response element signaling pathway. Neuroscience303, 489-502 (2015).

25. Wang, T. et al. Neuroprotective effects of Danshensu on rotenone-induced Parkinson's disease models in vitro and in vivo. BMC Complement Altern. Med.20, 1-10 (2020).

26. Dittmann, K., Gerhäuser, C., Klimo, K. \& Hamburger, M. HPLC-based activity profiling of Salvia miltiorrhiza for MAO A and iNOS inhibitory activities. Planta Med.70, 909-913 (2004).

27. Geha, R. M., Chen, K., Wouters, J., Ooms, F. \& Shih, J. C. Analysis of conserved active site residues in monoamine oxidase A and B and their three-dimensional molecular modeling. J. Biol. Chem.277, 1720917216 (2002).

28. De Colibus, L. et al. Three-dimensional structure of human monoamine oxidase A (MAO-A): relation to the structures of rat MAO-A and human MAO-B. Proc. Natl. Acad. Sci.102, 12684-12689 (2005).

29. Son, S.-Y. et al. Structure of human monoamine oxidase $A$ at 2.2- $\AA$ resolution: the control of opening the entry for substrates/inhibitors. Pediatria (Rio)105, 5739-5744 (2008).

30. van Westen, G. J., Wegner, J. K., IJzerman, A. P., van Vlijmen, H. W. \& Bender, A. Proteochemometric modeling as a tool to design selective compounds and for extrapolating to novel targets. MedChemComm2, 16-30 (2011).

31. Paricharak, S., Cortés-Ciriano, I., IJzerman, A. P., Malliavin, T. E. \& Bender, A. Proteochemometric modelling coupled to in silico target prediction: an integrated approach for the simultaneous prediction of polypharmacology and binding affinity/potency of small molecules. J. Cheminform.7, 1-11 (2015).

32. Cortés-Ciriano, I. et al. Polypharmacology modelling using proteochemometrics (PCM): recent methodological developments, applications to target families, and future prospects. MedChemComm6, 24-50 (2015).

33. Teague, S. J., Davis, A. M., Leeson, P. D. \& Oprea, T. The design of leadlike combinatorial libraries. Angew. Chem. Int. Ed.38, 3743-3748 (1999).

34. Ren, J., Fu, L., Nile, S. H., Zhang, J. \& Kai, G. Salvia miltiorrhiza in treating cardiovascular diseases: a review on its pharmacological and clinical applications. Front. Pharmacol.10 (2019).

35. Zhang, Y. et al. Tanshinones: sources, pharmacokinetics and anti-cancer activities. Int. J. Mol. Sci.13, 13621-13666 (2012).

36. Wang, Q. et al. Tanshinones inhibit amyloid aggregation by amyloid- $\beta$ peptide, disaggregate amyloid fibrils, and protect cultured cells. ACS Chem. Neurosci.4, 1004-1015 (2013). 
37. Tang, C., Xue, H., Bai, C., Fu, R. \& Wu, A. The effects of Tanshinone IIA on blood-brain barrier and brain edema after transient middle cerebral artery occlusion in rats. Phytomedicine17, 1145-1149 (2010).

38. Fowler, J. et al. Age-related increases in brain monoamine oxidase B in living healthy human subjects. Neurobiol. Aging18, 431-435 (1997).

39. Danielczyk, W., Streifler, M., Konradi, C., Riederer, P. \& Moll, G. Platelet MAO-B activity and the psychopathology of Parkinson's disease, senile dementia and multi-infarct dementia. Acta Psychiatr. Scand.78, 730-736 (1988).

40. Thal, D. M. et al. Crystal structures of the $\mathrm{M}_{1}$ and $\mathrm{M}_{4}$ muscarinic acetylcholine receptors. Nature531, 335340 (2016).

41. Wang, D. et al. Comparative pharmacokinetics and tissue distribution of cryptotanshinone, tanshinone IIA, dihydrotanshinone I, and tanshinone I after oral administration of pure tanshinones and liposoluble extract of Salvia miltiorrhiza to rats. Biopharm. Drug Dispos.41, 54-63 (2020).

42. Park, E.-J., Zhao, Y.-Z., Kim, Y.-C. \& Sohn, D. H. Preventive effects of a purified extract isolated from Salvia miltiorrhiza enriched with tanshinone I, tanshinone IIA and cryptotanshinone on hepatocyte injury in vitro and in vivo. Food Chem. Toxicol.47, 2742-2748 (2009).

43. Ryu, S. Y., Lee, C. O. \& Choi, S. U. In vitro cytotoxicity of tanshinones from Salvia miltiorrhiza. Planta Med.63, 339-342 (1997).

44. Park, J. H. et al. Anti-inflammatory effect of tanshinone I in neuroprotection against cerebral ischemiareperfusion injury in the gerbil hippocampus. Neurochem. Res.39, 1300-1312 (2014).

45. Tong, J. et al. Brain monoamine oxidase B and A in human parkinsonian dopamine deficiency disorders. Brain140, 2460-2474 (2017).

46. Moehle, M. S. \& Conn, P. J. Roles of the $\mathrm{M}_{4}$ acetylcholine receptor in the basal ganglia and the treatment of movement disorders. Mov. Disord.34, 1089-1099 (2019).

47. Tzavara, E. T. et al. $\mathrm{M}_{4}$ muscarinic receptors regulate the dynamics of cholinergic and dopaminergic neurotransmission: relevance to the pathophysiology and treatment of related central nervous system pathologies. FASEB J.18, 1410-1412 (2004).

48. Downs, A. M., Donsante, Y., Jinnah, H. \& Hess, E. J. Blockade of $M_{4}$ muscarinic receptors on striatal cholinergic interneurons normalizes striatal dopamine release in a mouse model of DYT1-TOR1A dystonia. bioRxiv (2020).

49. Kim, D. H. et al. Tanshinone congeners improve memory impairments induced by scopolamine on passive avoidance tasks in mice. Eur. J. Pharmacol.574, 140-147 (2007).

50. Mao, H. et al. Dual effects of lipophilic extract of Salvia miltiorrhiza (Danshen) on catecholamine secretion in cultured bovine adrenal medullary cells. J. Ethnopharmacol.125, 59-67 (2009).

51. Kim, D. H. et al. Tanshinone I enhances learning and memory, and ameliorates memory impairment in mice via the extracellular signal-regulated kinase signalling pathway. Br. J. Pharmacol.158, 1131-1142 (2009).

52. Kim, D. H. et al. Characterization of the inhibitory activity of natural tanshinones from Salvia miltiorrhiza roots on protein tyrosine phosphatase 1B. Chem.-Biol. Interact.278, 65-73 (2017). 
53. Seong, S. H. et al. Probing multi-target action of phlorotannins as new monoamine oxidase inhibitors and dopaminergic receptor modulators with the potential for treatment of neuronal disorders. Mar. Drugs17, 377 (2019).

54. Paudel, P., Park, S. E., Seong, S. H., Jung, H. A. \& Choi, J. S. Novel diels-alder type adducts from Morus alba root bark targeting human monoamine oxidase and dopaminergic receptors for the management of neurodegenerative diseases. Int. J. Mol. Sci.20, 6232 (2019).

55. Fauzi, F. M. et al. Understanding the mode-of-action of Cassia auriculata via in silico and in vivo studies towards validating it as a long term therapy for type II diabetes. J. Ethnopharmacol.197, 61-72 (2017).

56. Goodsell, D. S., Morris, G. M. \& Olson, A. J. Automated Docking of Flexible Ligands: Applications of AutoDock. J. Mol. Recognit.9, 1-5 (1996).

57. Pires, D. E., Blundell, T. L. \& Ascher, D. B. pkCSM: Predicting Small-Molecule Pharmacokinetic and Toxicity Properties Using Graph-Based Signatures. J. Med. Chem.58, 4066-4072 (2015).

58. Daina, A., Michielin, O. \& Zoete, V. SwissADME: A Free Web Tool to Evaluate Pharmacokinetics, DrugLikeness and Medicinal Chemistry Friendliness of Small Molecules. Sci. Rep.7, 42717 (2017).

\section{Tables}

Table 1. Inhibitory activities of tanshinone I, tanshinone IIA, and cryptotanshinone against recombinant human monoamine oxidase $A$ and $B$, and their enzyme kinetic parameters.

\begin{tabular}{|c|c|c|c|c|c|c|c|c|c|}
\hline \multirow[t]{2}{*}{ Compound } & \multicolumn{4}{|c|}{$\begin{array}{l}\text { Human monoamine oxidase } \mathrm{A} \\
(\mathrm{hMAO-A})\end{array}$} & \multirow[t]{2}{*}{$\mathrm{SI}^{b}$} & \multicolumn{4}{|c|}{$\begin{array}{l}\text { Human monoamine oxidase } \mathrm{B} \\
\text { (hMAO-B) }\end{array}$} \\
\hline & $\mathrm{IC}_{50}{ }^{\mathrm{a}}$ & $K_{\mathrm{ic}}^{c}$ & $K_{\mathrm{iu}}{ }^{c}$ & $\begin{array}{l}\text { Inhibition } \\
\text { type }{ }^{d}\end{array}$ & & $\mathrm{IC}_{50}{ }^{\mathrm{a}}$ & $K_{\mathrm{ic}}{ }^{\mathrm{c}}$ & $K_{\mathrm{iu}}{ }^{c}$ & $\begin{array}{l}\text { Inhibition } \\
\text { type }{ }^{d}\end{array}$ \\
\hline Tanshinone I & $\begin{array}{l}2.62 \\
\pm \\
0.52\end{array}$ & $\begin{array}{l}1.69 \\
\pm \\
0.19\end{array}$ & $\begin{array}{l}4.65 \\
\pm \\
0.16\end{array}$ & Mixed & 0.11 & $\begin{array}{l}24.9 \\
\pm \\
3.82\end{array}$ & $\begin{array}{l}25.6 \\
\pm \\
1.10\end{array}$ & $\begin{array}{l}17.4 \\
\pm \\
0.78\end{array}$ & Mixed \\
\hline Tanshinone IIA & $\begin{array}{l}6.08 \\
\pm \\
0.06\end{array}$ & $\begin{array}{l}0.72 \\
\pm \\
0.13\end{array}$ & $\begin{array}{l}2.74 \\
\pm \\
0.37\end{array}$ & Mixed & 0.35 & $\begin{array}{l}17.5 \\
\pm \\
0.89\end{array}$ & $\begin{array}{l}12.9 \\
\pm \\
1.14\end{array}$ & $\begin{array}{l}13.7 \\
\pm \\
0.58\end{array}$ & $\begin{array}{l}\text { Non- } \\
\text { competitive }\end{array}$ \\
\hline Cryptotanshinone & $\begin{array}{l}8.70 \\
\pm \\
0.06\end{array}$ & $\begin{array}{l}4.99 \\
\pm \\
0.34\end{array}$ & $\begin{array}{l}38.1 \\
\pm \\
1.79\end{array}$ & Mixed & 0.38 & $\begin{array}{l}23.1 \\
\pm \\
2.10\end{array}$ & $\begin{array}{l}9.33 \\
\pm \\
0.10\end{array}$ & - & Competitive \\
\hline I-Deprenyl. $\mathrm{HCl}^{e}$ & $\begin{array}{l}14.9 \\
\pm \\
0.38\end{array}$ & - & - & - & 78.8 & $\begin{array}{l}0.19 \\
\pm \\
0.02\end{array}$ & - & - & - \\
\hline
\end{tabular}

${ }^{a}$ The concentration required to produce $50 \%$ inhibition of hMAO-A/B activities ( $\mathrm{IC}_{50}$ values in $\mu \mathrm{M}$ ) was calculated using the log-dose inhibition curve and expressed as the mean $\pm S D$ of triplicate experiments. ${ }^{b}$ Selectivity index (ratio of $\mathrm{IC}_{50}$ value for hMAO-A inhibition to that for hMAO-B inhibition). ChMAO inhibition constants $\left(K_{\mathrm{ic}}\right.$ and $K_{\mathrm{iu}}$ values) were determined from secondary plots. ${ }^{d} \mathrm{hMAO}$ inhibition type was determined using Lineweaver-Burk and Dixon plots. ${ }^{e}$ Positive control. 
Table 2. List of top ten protein targets for tanshinone I, tanshinone IIA, and cryptotanshinone from computational proteochemometric modeling. ${ }^{a}$ NR: Normalization rate.

\begin{tabular}{|c|c|c|c|c|c|}
\hline Tanshinone I & $\mathrm{NR}^{a}$ & Tanshinone IIA & $\mathrm{NR}^{a}$ & Cryptotanshinone & $\mathrm{NR}^{a}$ \\
\hline $\begin{array}{l}\text { Gastrin/cholecystokinin } \\
\text { type B receptor }\end{array}$ & 0.96 & $\begin{array}{l}\text { Mitogen-activated protein kinase } \\
14\end{array}$ & 0.85 & $\begin{array}{l}\text { Mitogen- } \\
\text { activated protein } \\
\text { kinase } 14\end{array}$ & 0.95 \\
\hline $\begin{array}{l}\text { Somatostatin receptor } \\
\text { type } 2\end{array}$ & 0.95 & $\begin{array}{l}\text { Vascular endothelial growth } \\
\text { factor receptor } 1\end{array}$ & 0.73 & $\begin{array}{l}\text { Mitogen- } \\
\text { activated protein } \\
\text { kinase } 8\end{array}$ & 0.85 \\
\hline Endothelin-1 receptor & 0.94 & $\begin{array}{l}\text { Mitogen-activated protein kinase } \\
8\end{array}$ & 0.71 & $\begin{array}{l}\text { Hepatocyte } \\
\text { growth factor } \\
\text { receptor }\end{array}$ & 0.74 \\
\hline $\begin{array}{l}\text { Muscarinic } \\
\text { acetylcholine receptor } \\
\text { M4 }\end{array}$ & 0.92 & Vasopressin V1b receptor & 0.70 & $\begin{array}{l}\text { Vasopressin V1b } \\
\text { receptor }\end{array}$ & 0.73 \\
\hline $\begin{array}{l}\text { Muscarinic } \\
\text { acetylcholine receptor } \\
\text { M2 }\end{array}$ & 0.92 & $\begin{array}{l}\text { Hepatocyte growth factor } \\
\text { receptor }\end{array}$ & 0.67 & $\begin{array}{l}\text { Prostaglandin } \\
\text { G/H synthase } 2\end{array}$ & 0.68 \\
\hline B1 bradykinin receptor & 0.92 & $\begin{array}{l}\text { Sodium-dependent serotonin } \\
\text { transporter }\end{array}$ & 0.65 & $\begin{array}{l}\text { Vascular } \\
\text { endothelial } \\
\text { growth factor } \\
\text { receptor } 1\end{array}$ & 0.68 \\
\hline Histamine $\mathrm{H} 1$ receptor & 0.92 & $\begin{array}{l}\text { RAC-beta serine/threonine-protein } \\
\text { kinase }\end{array}$ & 0.61 & $\begin{array}{l}\text { Type-1 } \\
\text { angiotensin II } \\
\text { receptor }\end{array}$ & 0.67 \\
\hline $\begin{array}{l}\text { 5-hydroxytryptamine } \\
\text { receptor } 2 \mathrm{~A}\end{array}$ & 0.92 & $\begin{array}{l}\text { Phosphatidylinositol } 4,5- \\
\text { bisphosphate 3-kinase catalytic } \\
\text { subunit alpha isoform }\end{array}$ & 0.61 & $\begin{array}{l}\text { Vitamin D3 } \\
\text { receptor }\end{array}$ & 0.67 \\
\hline $\begin{array}{l}\text { Type-1 angiotensin II } \\
\text { receptor }\end{array}$ & 0.92 & $\begin{array}{l}\text { Proto-oncogene tyrosine-protein } \\
\text { kinase Src }\end{array}$ & 0.61 & $\begin{array}{l}\text { Receptor } \\
\text { tyrosine-protein } \\
\text { kinase erbB-2 }\end{array}$ & 0.67 \\
\hline $\begin{array}{l}\text { Beta-1 adrenergic } \\
\text { receptor }\end{array}$ & 0.91 & $\begin{array}{l}\text { RAC-alpha serine/threonine- } \\
\text { protein kinase }\end{array}$ & 0.61 & $\begin{array}{l}\text { RAC-beta } \\
\text { serine/threonine- } \\
\text { protein kinase }\end{array}$ & 0.67 \\
\hline
\end{tabular}

Table 3. Percentage stimulation and percentage inhibition of human muscarinic acetylcholine receptors by tanshinone I. 


\begin{tabular}{|c|c|c|c|c|}
\hline Receptors & $\%$ Stimulation ${ }^{a}$ & $(\% \text { Inhibition })^{b}$ & $\begin{array}{l}\text { Reference agonist }^{c} \\
\text { (Reference antagonist) }^{d}\end{array}$ & $\begin{array}{l}\text { Reference } \mathrm{EC}_{50} e \\
\left(\mathrm{IC}_{50}\right)^{f}\end{array}$ \\
\hline $\mathrm{M}_{1}$ & $2.5 \pm 0.21$ & $13.8 \pm 1.98$ & $\begin{array}{l}\text { Acetylcholine } \\
\text { (Pirenzepine) }\end{array}$ & $\begin{array}{l}0.6 \\
(49)\end{array}$ \\
\hline $\mathrm{M}_{2}$ & $12.6 \pm 3.61$ & $35.8 \pm 4.74$ & $\begin{array}{l}\text { Acetylcholine } \\
\text { (Methoctramine) }\end{array}$ & $\begin{array}{l}70 \\
(140)\end{array}$ \\
\hline$M_{3}$ & $-2.3 \pm 0.21$ & $3.3 \pm 11.24$ & $\begin{array}{l}\text { Acetylcholine } \\
\text { (4-DAMP) }\end{array}$ & $\begin{array}{l}27 \\
(4.1)\end{array}$ \\
\hline $\mathrm{M}_{4}$ & $-23.5 \pm 1.48$ & $56.1 \pm 2.40$ & $\begin{array}{l}\text { Acetylcholine } \\
\text { (PD 102807) }\end{array}$ & $\begin{array}{l}26 \\
(36)\end{array}$ \\
\hline$M_{5}$ & $-1.6 \pm 0.85$ & $-0.5 \pm 0.42$ & $\begin{array}{l}\text { Acetylcholine } \\
\text { (Atropine sulfate) }\end{array}$ & $\begin{array}{l}2 \\
(2.1)\end{array}$ \\
\hline
\end{tabular}

$a \%$ stimulation represents the percentage of control agonist response by tanshinone I at $100 \mu \mathrm{M} .{ }^{b} \%$ inhibition represents percentage inhibition of control agonist response by tanshinone I at $100 \mu \mathrm{M}$. ${ }^{c}$ Reference agonists and ${ }^{d}$ reference antagonists used in the assay. ${ }^{e} \mathrm{EC}_{50}$ value of reference agonist (nM). ${ }^{1} \mathrm{C}_{50}$ value of reference antagonist (nM). 4-DAMP: 1,1-Dimethyl-4-diphenylacetoxypiperidinium iodide.

Table 4. Prediction of pharmacokinetic parameters and toxicity of tanshinone I.

\begin{tabular}{|c|c|}
\hline Parameters & Compound: Tanshinone I \\
\hline Drug-likeness & Yes \\
\hline Lead-likeness & No; 1 violation: XLOGP3 > 3.5 \\
\hline $\log \mathrm{Po} / \mathrm{w}^{a}$ & 2.44 \\
\hline Solubility ${ }^{b}$ & -6.91 \\
\hline$H \mathrm{H}^{c}$ & $98.91 \%$ \\
\hline Caco-2 permeability ${ }^{d}$ & 1.401 \\
\hline BBB permeability ${ }^{e}$ & Yes (0.447) \\
\hline CNS permeability ${ }^{f}$ & -1.446 \\
\hline AMES toxicity & Yes \\
\hline Hepatotoxicity & No \\
\hline
\end{tabular}


${ }^{a}$ Log of the coefficient for solvent partitioning between 1-octanol and water. ${ }^{b}$ LogS scale: Insoluble $<-10<$ Poorly $<-6<$ Moderately $<-4<$ Soluble $<-2<$ Very $<0<$ Highly. Muman intestinal absorption: If $<30 \%$, poorly absorbed. ${ }^{d}$ Caco-2 permeability is high if it has Papp $>8 \times 10^{-6} \mathrm{~cm} / \mathrm{s}$. ${ }^{e}$ Log BB $>0.3$ is considered to readily cross blood-brain barrier while $\log B B<-1$ was considered to be poorly distributed to the brain. ${ }^{\prime}$ Log PS $>-2$ is considered to penetrate the central nervous system (CNS) while log PS $<-3$ considered unable to penetrate the CNS.

\section{Figures}<smiles>Cc1coc2c1C(=O)C(=O)c1c-2ccc2c(C)cccc12</smiles>

1<smiles>Cc1coc2c1C(=O)C(=O)c1c-2ccc2c1CCCC2(C)C</smiles>

2<smiles>C[C@H]1COC2=C1C(=O)C(=O)c1c2ccc2c1CCCC2(C)C</smiles>

3

\section{Figure 1}

Chemical structures of tanshinone I (1), tanshinone IIA (2), and cryptotanshinone (3) isolated from Salvia miltiorrhiza. 
a
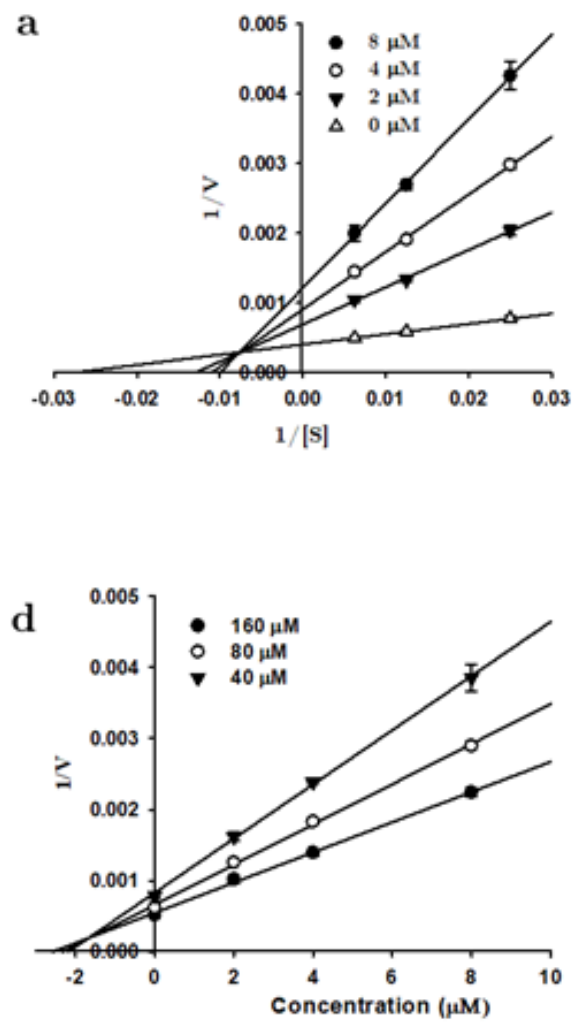

b

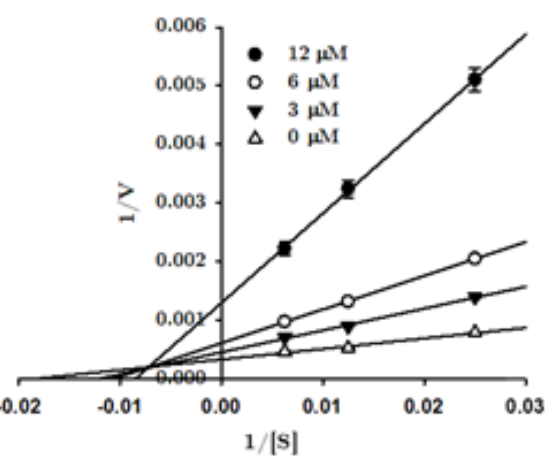

e

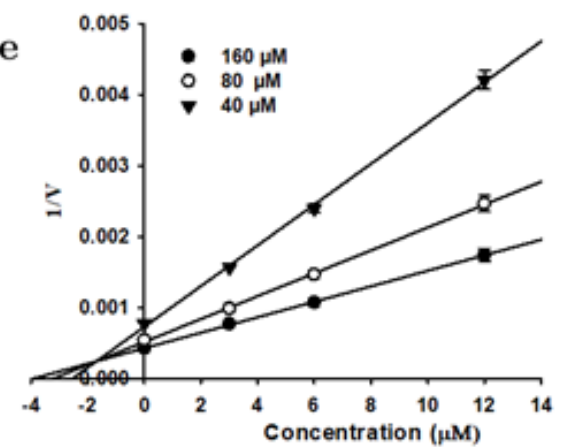

c
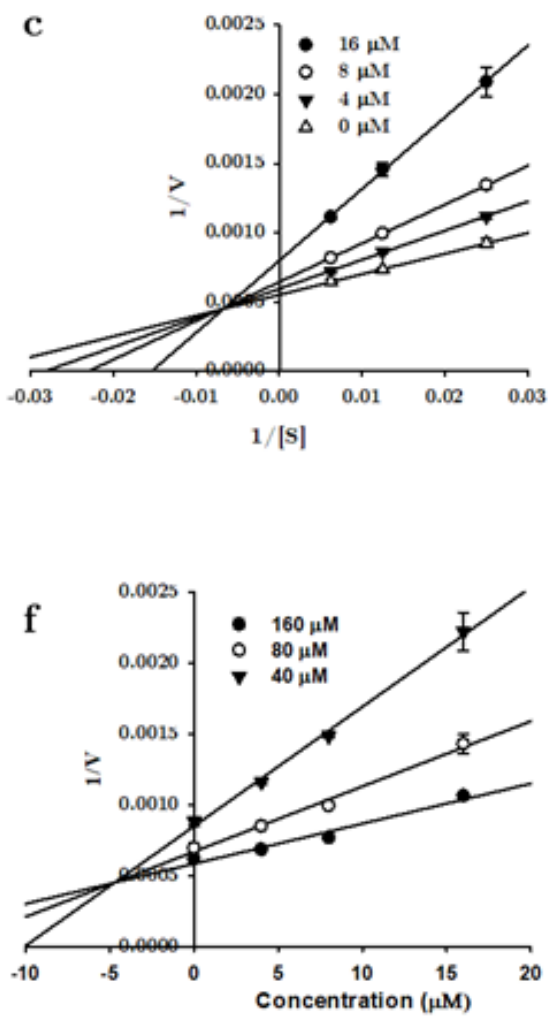

Figure 2

Lineweaver-Burk (a, b, and c) and Dixon ( $d, e$, and f) plots of tanshinone I, tanshinone IIA, and cryptotanshinone for hMAO-A inhibition, respectively.

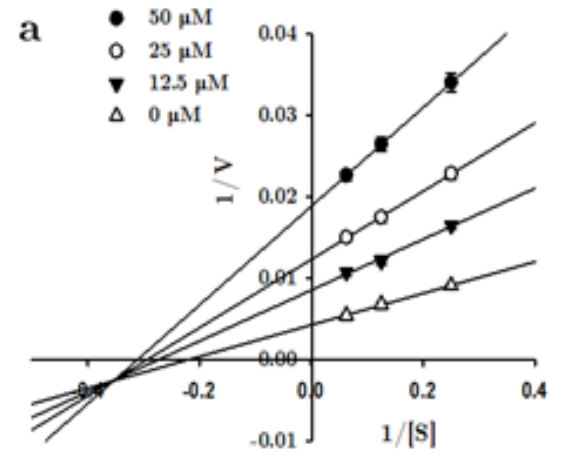

d

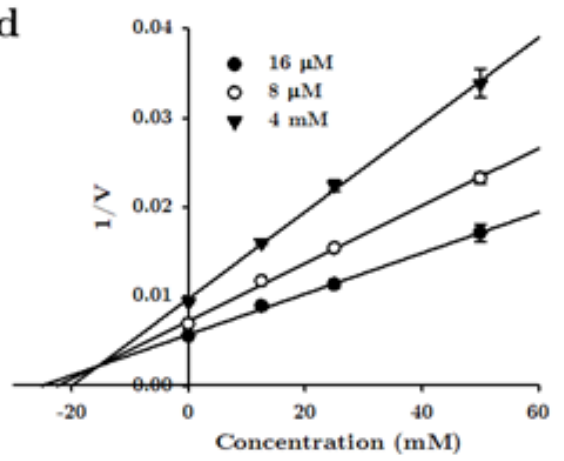

b

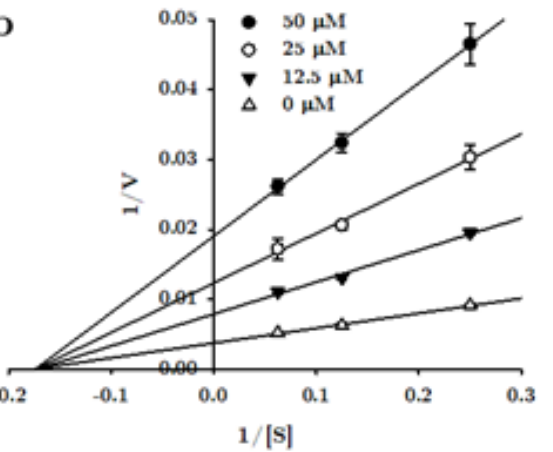

e

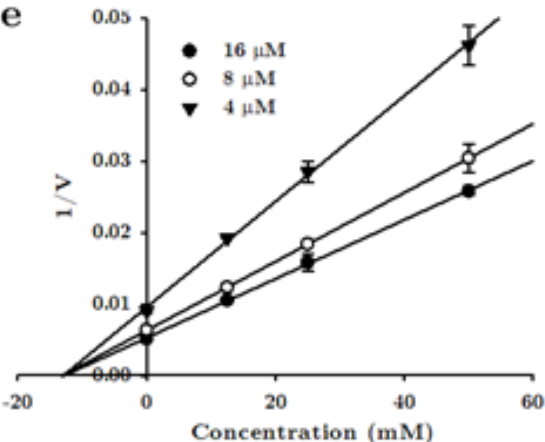

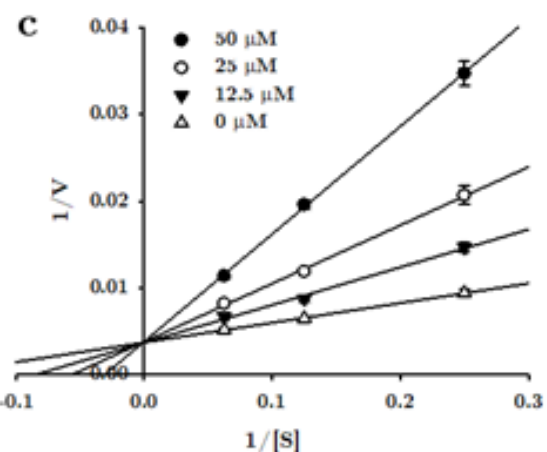

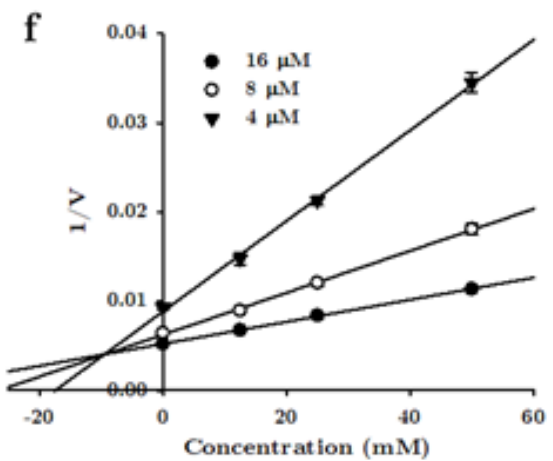

Figure 3 
Lineweaver-Burk (a, b, and c) and Dixon ( $d, e$, and f) plots of tanshinone I, tanshinone IIA, and cryptotanshinone for hMAO-B inhibition, respectively.

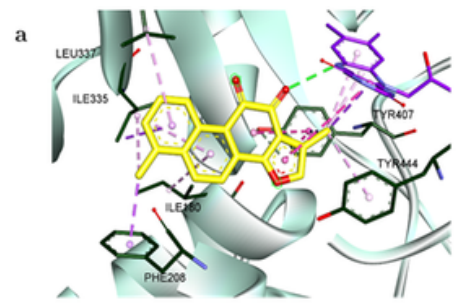

b

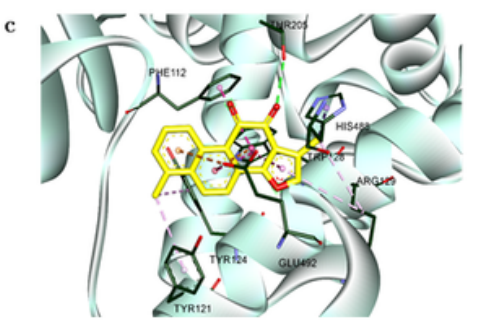

e

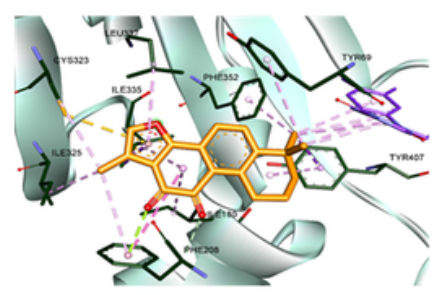

g
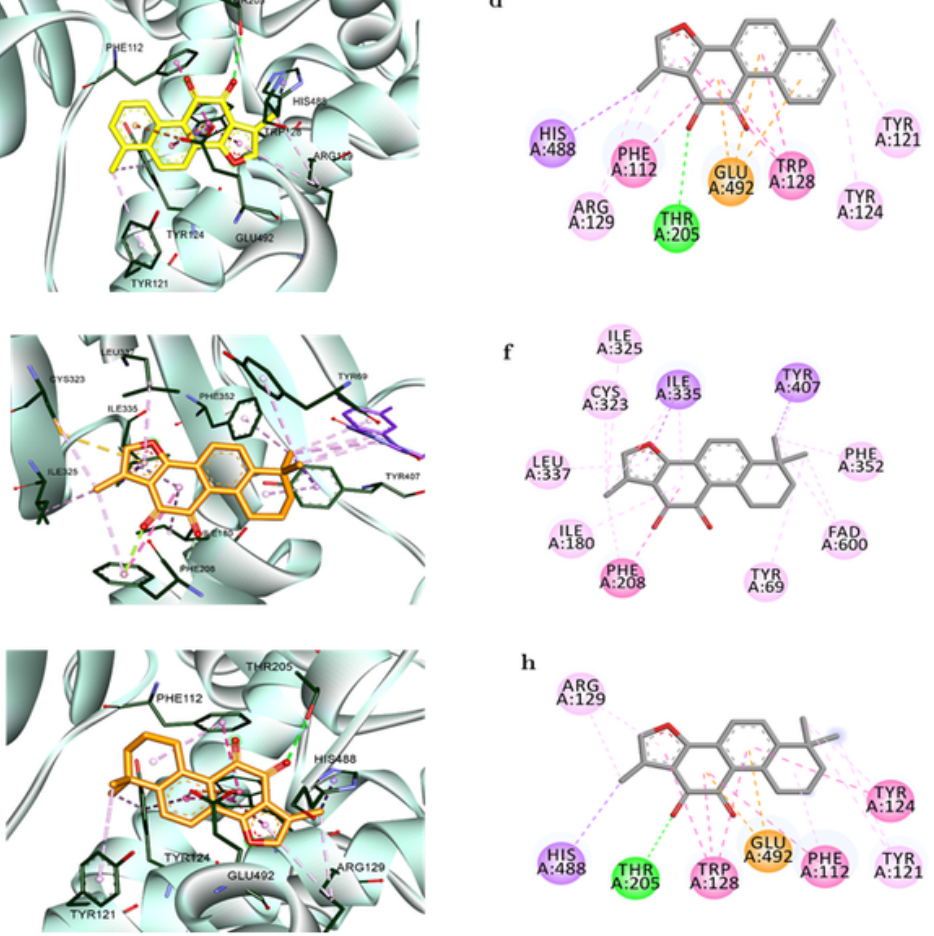

f $\quad$ A: $: 325$

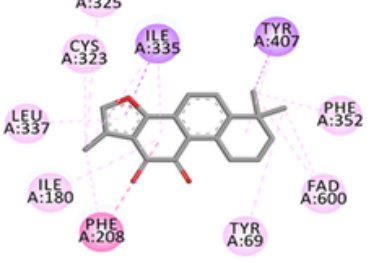

h

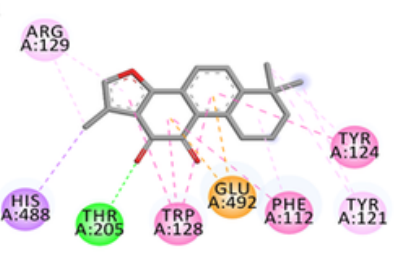

i

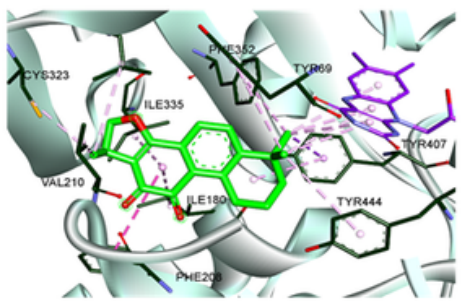

k
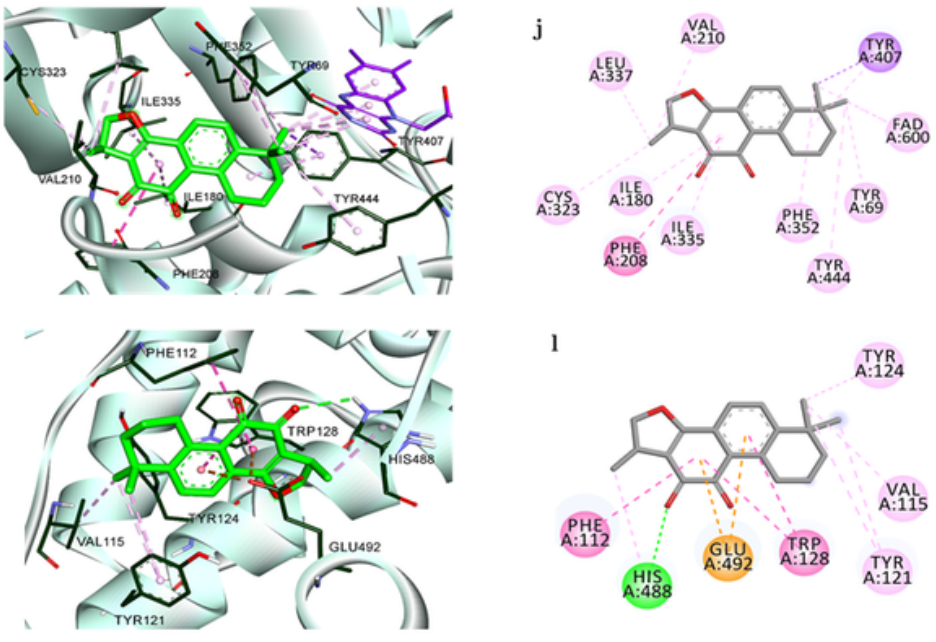

A:323
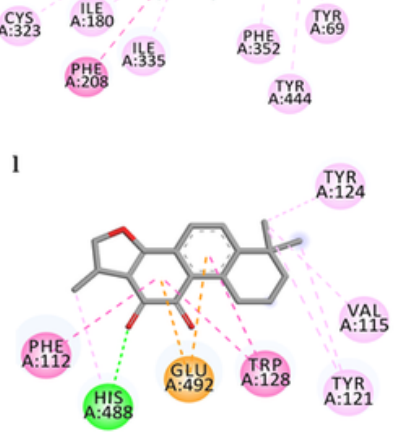

\section{Figure 4}

Prediction of binding modes of tanshinones with hMAO-A by molecular docking. Close-up view of tanshinone I (yellow), tanshinone IIA (brown), and cryptotanshinone (green) at the catalytic (a, e, and i) and allosteric (c, $\mathrm{g}$, and $\mathrm{k}$ ) binding sites of hMAO-A, respectively. Two dimensional-binding diagrams showing ligand-enzyme 
interactions for tanshinone I, tanshinone IIA, and cryptotanshinone at the catalytic (b, $\mathrm{f}$, and $\mathrm{j})$ and allosteric $(d, h$, and I) sites of hMAO-A, respectively.

a

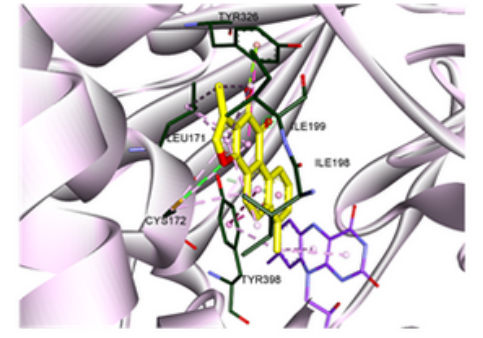

c

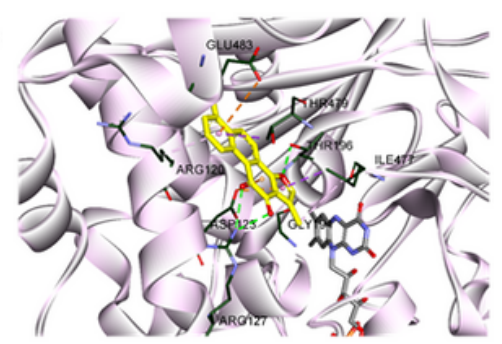

e

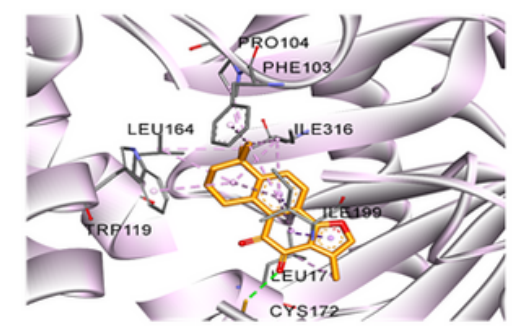

g

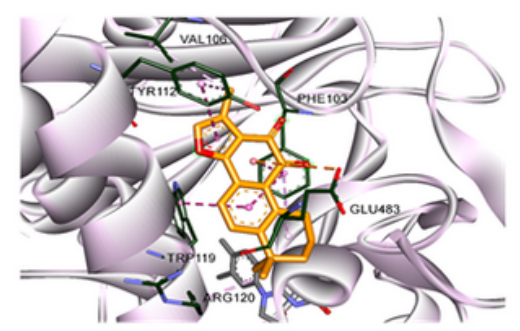

i

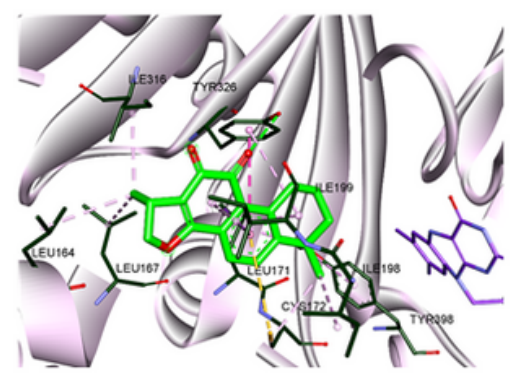

b
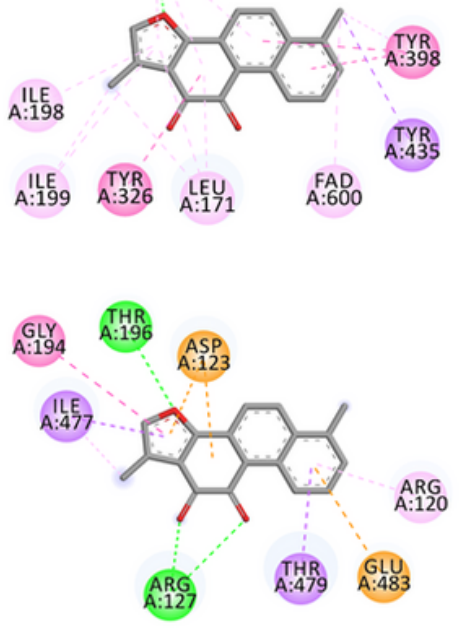

f

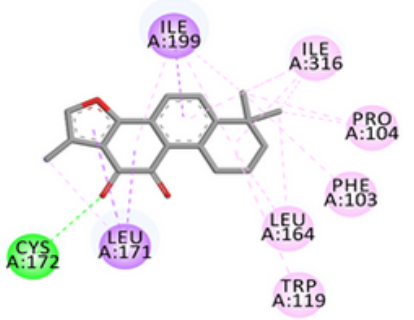

h

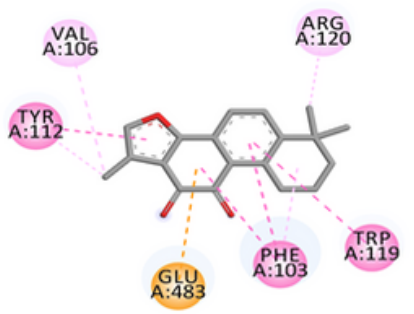

j

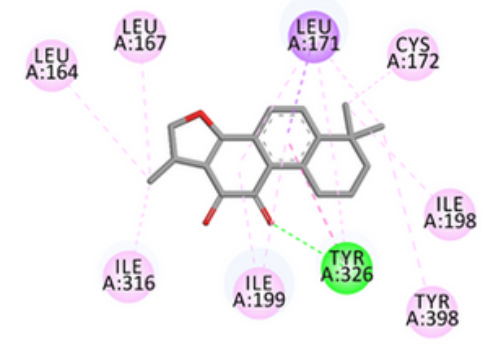

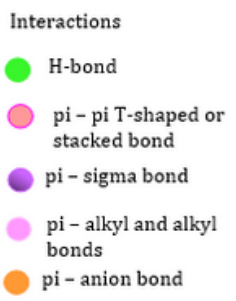

pi-anion bond

\section{Figure 5}

Prediction of binding modes of tanshinones with hMAO-B by molecular docking. Close-up view of compounds tanshinone I (yellow), tanshinone IIA (brown), and cryptotanshinone (green) at the catalytic (a, e, and i) and allosteric (c and g) binding sites of hMAO-B, respectively. Two dimensional-binding diagrams 
showing the ligand-enzyme interactions for tanshinone I, tanshinone IIA, and cryptotanshinone at the catalytic (b, f, and j) and allosteric ( $d$ and $h$ ) sites of hMAO-B, respectively.

a.

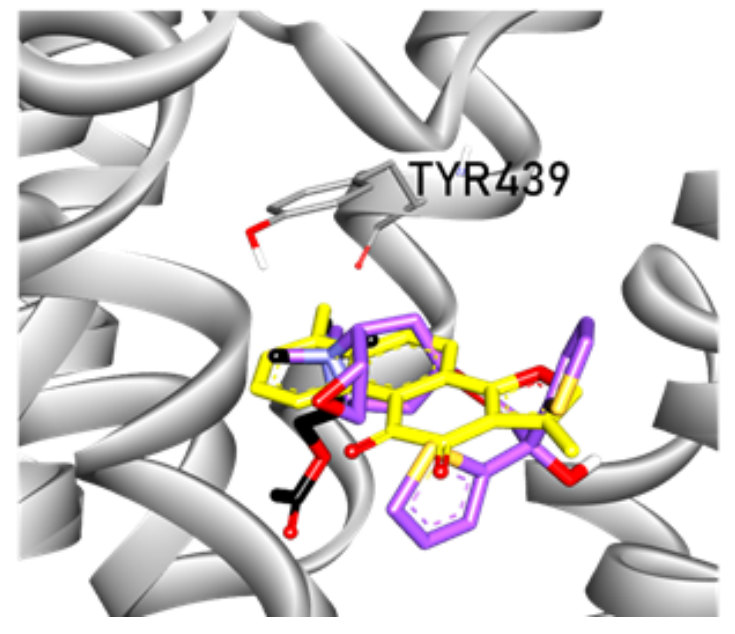

b.

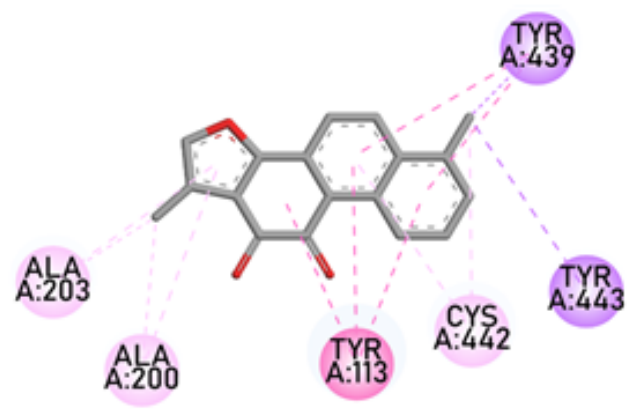

Interactions

pi - pi T-shaped or stacked bond

pi - sigma bond

$\mathrm{pi}-$ alkyl and alkyl bonds

\section{Figure 6}

Prediction of binding modes of tanshinone I with hM4R by molecular docking. Close-up view of tanshinone I at the orthosteric binding site of hM4R (a). Tanshinone I, acetylcholine, and tiotropium are shown as yellow, black, and purple sticks, respectively. A two dimensional-binding diagram showing the ligand-receptor interactions at the catalytic hM4R by tanshinone I (b).

\section{Supplementary Files}

This is a list of supplementary files associated with this preprint. Click to download.

- SupplementaryInformationMonoamineoxidaseinhibitionbymajortanshinonesfromSalviamiltiorrhiza.docx 